\title{
Serum isoamylase activities in diabetes mellitus
}

\author{
YING FOO, SB ROSALKI, L RAMDIAL, D MIKHAILIDIS, AND P DANDONA \\ From the Department of Chemical Pathology, Royal Free Hospital, London, UK
}

SUMMARY Serum pancreatic isoamylase activities were used to assess exocrine pancreatic function in 39 patients with diabetes mellitus ( 21 on insulin, 12 on sulphonylureas, and six on biguanides or diet), and the results were compared with serum immunoreactive trypsin concentrations. Thirteen patients had decreased pancreatic isoamylase activity, the insulin-dependent diabetics showing the highest incidence of abnormality. This incidence of abnormality is similar to that previously described for serum immunoreactive trypsin, and the two procedures gave excellent overall correlation $(r=0.9)$. Our observations offer further evidence that pancreatic exocrine function is impaired in diabetes mellitus. Serum isoamylase determination provides a convenient, inexpensive, and rapid procedure for its detection.

Patients with diabetes mellitus have been shown by duodenal enzyme studies ${ }^{1-5}$ and by serum immunoreactive trypsin (IRT) measurement ${ }^{6}$ to have impaired pancreatic exocrine function, the incidence being highest in insulin-dependent patients. Serum amylase activity normally derives from both the pancreas and the salivary glands, but the pancreatic isoenzyme is reduced when pancreatic exocrine function is deficient, ${ }^{7-9}$ and pancreatic isoamylase determination provides a convenient non-invasive test for such deficiency. We have, therefore, measured serum pancreatic isoamylase activity in diabetics and have compared the results with serum IRT levels.

\section{Material and methods}

Sera from 39 patients aged 24 to 77 years (19 men, 20 women) with diabetes mellitus were studied. They were classified on the basis of treatment: 21 on insulin, 12 on sulphonylureas, and six on diet or biguanide therapy. Occasional patients on sulphonylureas had also received biguanides but no subjects classified as on biguanides had received sulphonylureas. Reference values were obtained from 100 apparently healthy blood donors (50 men and 50 women).

Samples were separated on Beckman cellulose acetate membrane using the Beckman Microzone System (Beckman Instrument Inc, Fullerton, California, USA) in a discontinuous barbitone/

Received for publication 12 March 1980
Tris-EDTA-borate buffer system; $0 \cdot 25-2.5 \mu$ l of sample was applied near the anode end of the strip, the volume of sample depending on total amylase activity. For samples with serum amylase activity of less than $200 \mathrm{U} / 1,2.5 \mu \mathrm{l}$ of sample was applied. With samples of higher activity the volume applied was reduced by $0.5 \mu \mathrm{l}$ for each $100 \mathrm{U} / \mathrm{l}$ of amylase activity. Control specimens of acute pancreatitis serum and saline-diluted saliva were included in each run. Electrophoresis was carried out at $4^{\circ} \mathrm{C}$ at a constant voltage of $250 \mathrm{~V}$ for $1 \frac{1}{2}$ hours, after which the cellulose acetate membrane was layered on to the surface of a dyed starch substrate incorporated into an agar gel and incubated at $37^{\circ} \mathrm{C} .1011$ The time of incubation was adjusted to give adequate staining, as judged by visual inspection, isoamylases showing as sharp blue-staining bands. The membrane was allowed to air dry, and the isoamylases were quantitated by reflectance densitometry with a Corning densitometer model 720 (Corning Medical, Medfield, Mass, USA), which gave the proportion of the pancreatic and salivary isoamylase fractions as percentages of the total amylase activity.

Serum total amylase activity (upper reference limit $312 \mathrm{U} / 1$ at $37^{\circ} \mathrm{C}$ ) was determined by the Phadebas method at $37^{\circ} \mathrm{C}$, and the pancreatic and salivary isoamylase activities were calculated from the total activity multiplied by the pancreatic or salivary isoamylase percentage respectively.

Serum immunoreactive trypsin (reference range $140-390 \mu \mathrm{g} / \mathrm{l}$ ) was measured by radioimmunoassay using a commercial kit (Hoechst UK Ltd, Hounslow, Middlesex, UK). 


\section{Results}

Isoamylase staining was demonstrated solely in the gamma globulin region. Clear separation of pancreatic (P) and salivary (S) isoamylase and their subfractions was obtained, pancreatic isoamylase showing greater mobility towards the cathode (Fig. 1). The analytical precision of the separation and quantitation procedure was determined from 10 runs of eight identical samples, and yielded an average within-batch coefficient of variation of $5 \%$ and between-batch coefficient of variation of $6 \%$ at a mean pancreatic isoamylase activity of $46 \mathrm{U} / \mathrm{l}$ at $37^{\circ} \mathrm{C}$.

Reference values for total amylase, pancreatic, and salivary isoamylase in the blood donor controls, calculated after exclusion of three outliers, are given in Table 1. The total serum amylase, pancreatic, and salivary isoamylase activities each showed a normal distribution with no sex difference detected in the total serum amylase and salivary isoamylase. The reference values for the total serum amylase and salivary isoamylase ranged from 106 to $312 \mathrm{U} / \mathrm{l}$ and 13 to $177 \mathrm{U} / 1$ at $37^{\circ} \mathrm{C}$ with mean values of $209 \mathrm{U} / 1$ and $95 \mathrm{U} / 1$, respectively. Mean pancreatic isoamylase $(108 \mathrm{U} / \mathrm{l})$ was significantly lower $(\mathrm{P}<0.02)$ in men than in women $(122 \mathrm{U} / \mathrm{l})$. Serum pancreatic isoamylase of less than $54 \mathrm{U} / 1$ in men or $72 \mathrm{U} / 1$ in women
Table 1 Reference values for serum amylase, pancreatic, and salivary isoamylase activities (mean $\pm S D$ )

\begin{tabular}{lccc}
\hline & All subjects (97) & Men (48) & Women (49) \\
\hline $\begin{array}{l}\text { Total serum amylase } \\
(\mathrm{U} / \mathrm{l})\end{array}$ & $209 \pm 52$ & $205 \pm 41$ & $213 \pm 61$ \\
$\begin{array}{l}\text { Pancreatic isoamylase } \\
(\mathrm{U} / \mathrm{l})\end{array}$ & $115 \pm 27$ & $108 \pm 27^{*}$ & $122 \pm 25^{*}$ \\
$\begin{array}{l}\text { Salivary isoamylase } \\
\text { a }\end{array}$ & $95 \pm 41$ & $97 \pm 57$ & $93 \pm 44$ \\
\hline
\end{tabular}

* Male cf female $P<0.02$.

was considered subnormal and regarded as indicative of impaired pancreatic exocrine function.

In the diabetics (Table 2), no significant difference was seen in mean total serum amylase activity between the three treatment groups, and no subnormal values were observed, though three diabetics on insulin and three on sulphonylureas had increased total activity. Mean pancreatic isoamylase activity was significantly reduced $(P<0.001)$ in the insulindependent diabetics and in the female patients treated with sulphonylureas. Ten out of 21 patients on insulin, 2/12 on sulphonylureas, and $1 / 6$ on diet had subnormal serum pancreatic isoamylase activity (Fig. 2). Overall, serum pancreatic isoamylase was subnormal in $13 / 39$ patients $(33 \%)$. For comparison, serum IRT levels were low in $9 / 21,3 / 12$, and $1 / 6$ of the respective treatment groups and in $13 / 39$

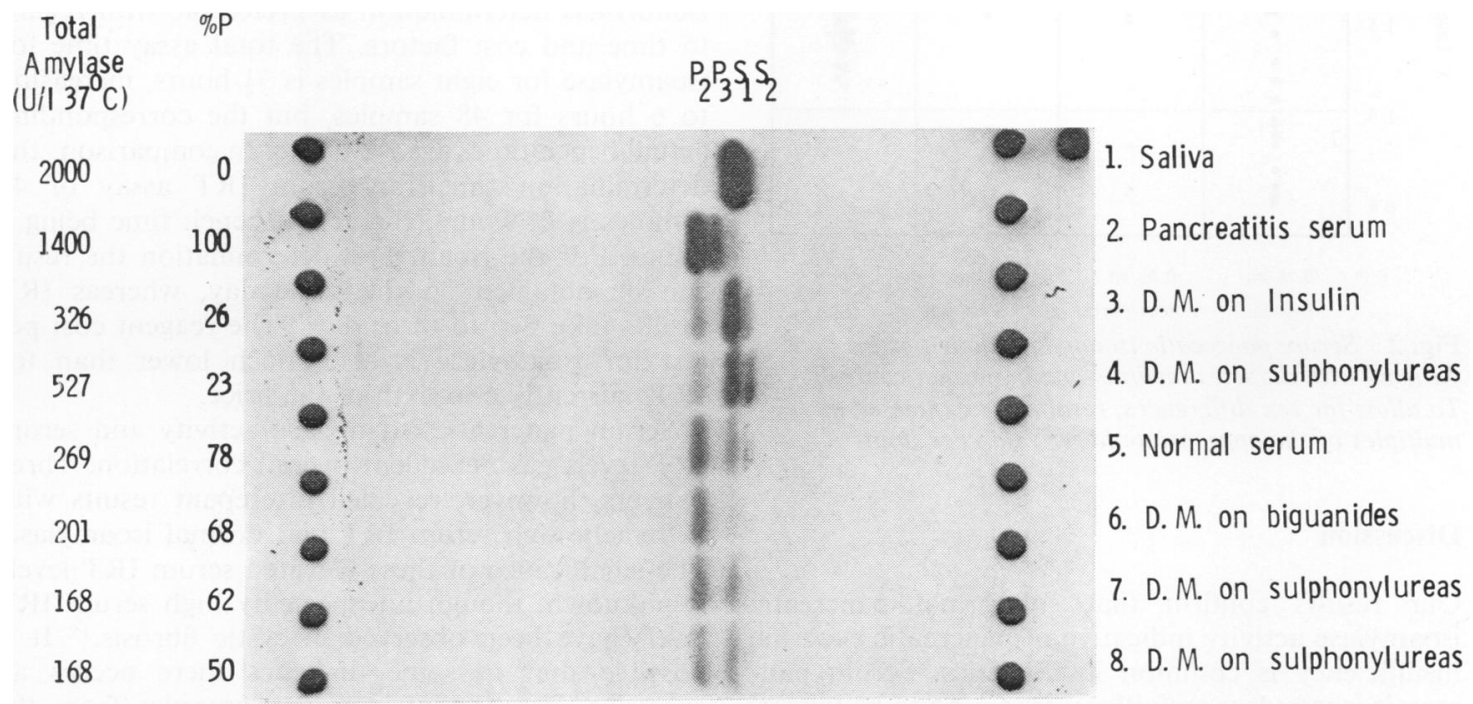

Fig. 1 Isoamylase patterns in normal serum (No. 5), salivary and pancreatitis serum markers (Nos 1 and 2), and patient sera are shown. Clear separation of pancreatic $\left(P_{2} P_{3}\right)$ and salivary $\left(S_{1} S_{2}\right)$ fractions is seen. 
Table 2 Mean total and pancreatic isoamylase activities in diabetics and controls

\begin{tabular}{lrlcc}
\hline & No. & $\begin{array}{l}\text { Total amylase } \\
(U / l)\end{array}$ & \multicolumn{2}{l}{$\begin{array}{l}\text { Pancreatic } \\
(\text { U } / l)\end{array}$} \\
\cline { 3 - 5 } & & & Men & Women \\
\hline Insulin & 21 & 235 & $77^{*}$ & $80^{*}$ \\
Sulphonylureas & 12 & 271 & 123 & $72^{*}$ \\
Diet/biguanides & 6 & 236 & 125 & 105 \\
Controls & 97 & 209 & 108 & 122 \\
\hline
\end{tabular}

*Patients cf controls $\mathrm{P}<0.001$

patients (33\%) overall. Salivary isoamylase was increased in $5 / 21$ patients on insulin, in $4 / 12$ on sulphonylureas, and in 9/39 patients overall.

Serum pancreatic isoamylase activity and serum IRT levels showed excellent overall correlation, with a coefficient of correlation on 36 patients of 0.9 (Fig. 3). Three patients showed widely discrepant values (see Discussion), and these were excluded from this calculation.

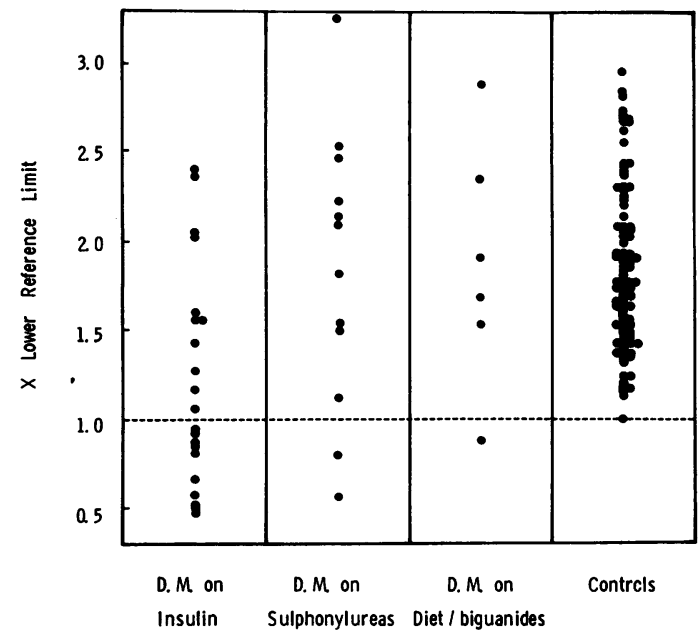

Fig. 2 Serum pancreatic isoamylase activities in patients with diabetes mellitus and in normal controls. To allow for sex differences, results are expressed as multiples of the appropriate lower reference limit.

\section{Discussion}

Our results confirm that subnormal pancreatic isoamylase activity indicative of pancreatic exocrine insufficiency is common in diabetics. Serum pancreatic isoamylase activities were found to be lowest, and subnormal values were more prevalent in the insulin-dependent diabetics, intermediate in patients treated with sulphonylureas, and no different from the controls in those milder diabetics treated with

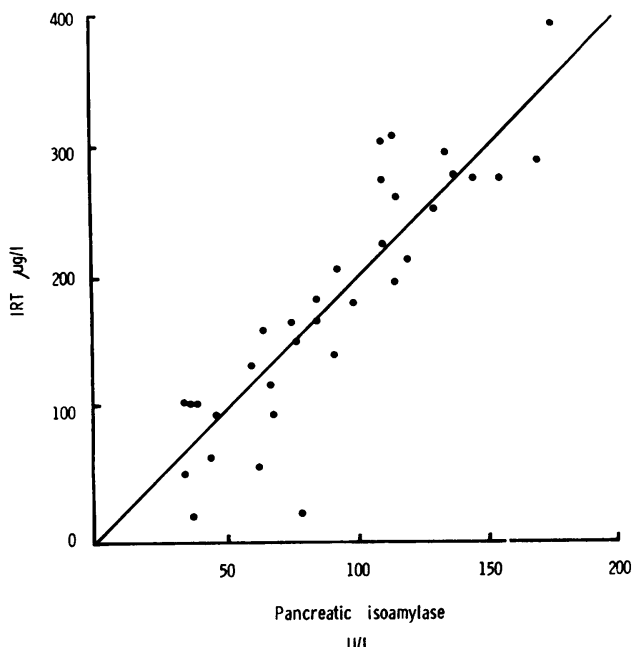

U/I

Fig. 3 Correlation between serum pancreatic isoamylase and immunoreactive trypsin (IRT) levels. The correlation coefficient is $0 \cdot 9$.

diet or biguanides. These observations are similar to those obtained with serum IRT in diabetics, ${ }^{6}$ and offer furthur evidence that the degree of pancreatic exocrine deficit in diabetes parallels the degree of impairment of endocrine function.

In our patients, the incidence of subnormal pancreatic isoamylase values was similar to that of reduced serum IRT levels. However, we regard isoamylase determination as preferable with regard to time and cost factors. The total assay time for isoamylase for eight samples is $3 \frac{1}{2}$ hours, increasing to 6 hours for 48 samples, but the corresponding actual bench times are 1-3 hours. In comparison, the determination time for serum IRT assay of 43 samples is 28 hours, the actual bench time being 3 hours. For the isoamylase determination the result can be obtained on the same day, whereas IRT results take two to three days. The reagent cost per test for isoamylase is also much lower than for IRT, currently one-sixth of the price.

Serum pancreatic isoamylase activity and serum IRT levels gave excellent overall correlation. Three patients, however, revealed discrepant results with extremely high serum IRT and normal isoamylase. The significance of these elevated serum IRT levels is unknown, though unexpectedly high serum IRT levels have been observed in cystic fibrosis. ${ }^{12}$ It is possible that in some diabetics there occurs an excessive secretion of zymogen granules from the pancreatic acini, as in cystic fibrosis, ${ }^{13}$ and that the immunoreactive enzyme contained in these granules is not biologically active.

Two diabetics (one on insulin and one on sul- 
phonylureas) showed reduced pancreatic isoamylase and an increase in salivary isoamylase. Seven other diabetics also had elevated salivary isoamylase activity, and in five this was sufficient to result in increased total serum amylase activity. The reason for the increase in salivary isoamylase is unknown. We are currently investigating whether salivary glands secrete amylase at an enhanced rate in diabetic patients.

In conclusion, serum isoamylase determination provides a rapid, inexpensive, and convenient non-invasive test for the investigation of pancreatic exocrine function and correlates well with measurement of serum IRT levels. Our high incidence of subnormal isoamylase activity in the serum of diabetics provides further evidence that pancreatic exocrine function is frequently impaired in diabetes mellitus and demonstrates that serum isoamylase determination is valuable for its detection.

We gratefully acknowledge the assistance of Dr TE Cleghorn who provided sera from blood donors.

\section{References}

${ }^{1}$ Chey WY, Shay H, Shuman CR. External pancreatic secretion in diabetes mellitus. Ann Intern Med 1963;59: 812-21.

Vacca JB, Henke WJ, Knight WA. The exocrine pancreas in diabetes mellitus. Ann Intern Med 1964;61:242-7.

${ }^{3}$ Baron JH, Nabarro JDN. Pancreatic exocrine function in maturity onset diabetes mellitus. Br Med J 1973;4:25-7.

${ }^{4}$ Domschke W, Tympner F, Domschke S, Demling L. Exocrine pancreatic function in juvenile diabetics. Am J Dig Dis 1975;20:309-12.

${ }^{5}$ Frier BM, Saunders JHB, Wormsley KG, Bouchier IAJ. Exocrine pancreatic function in juvenile-onset diabetes. Gut 1976;17:685-91.

${ }^{6}$ Dandona P, Elias E, Beckett AG. Serum trypsin concentrations in diabetes mellitus. $\mathrm{Br}$ Med J 1978;2:1125-7.

${ }^{7}$ Aw SE, Hobbs JR, Wootton IDP. Urinary isoamylase in the diabnosis of chronic pancreatitis. Gut 1967;8:402-7.

${ }^{8}$ Taussig LM, Wolf RO, Woods RE, Deckelbaum RJ. Use of serum amylase isoenzymes in evaluation of pancreatic function. Pediatrics 1974;54:229-35.

${ }^{9}$ Kamaryt J, Stejskal J, Osickova L. Urinary isoamylase in juvenile diabetics. J Clin Chem Clin Biochem 1978;16: 539-41.

${ }^{10}$ Rosalki SB. A direct staining technique for amylase isoenzyme demonstration. J Clin Pathol 1970;23:373-4.

${ }^{11}$ Davies TJ. A fast technique for the separation and detection of amylase isoenzyme using a chromogenic substrate. J Clin Pathol 1972;25:266-7.

12 Dandona P, Hodson M, Bell J, Ramdial L, Batten JC. Serum immunoreactive trypsin concentrations in cystic fibrosis. Lancet 1979;1:1032.

${ }^{13}$ Blomfield J, Dascalu J, van Lenneo EE, Brown JM. Hypersecretion of zymogen granules in the pathogenesis of cystic fibrosis. Gut 1973;14:558-65.

Requests for reprints to: Miss AY Foo, Department of Chemical Pathology, Royal Free Hospital, Pond Street, London NW3 2QG, UK. 